\title{
Design and optimization of air bottoming cycles for waste heat recovery in off-shore platforms
}

\author{
Pierobon, Leonardo; Haglind, Fredrik
}

Published in:

Applied Energy

Link to article, DOI:

10.1016/j.apenergy.2013.12.026

Publication date:

2014

Link back to DTU Orbit

Citation (APA):

Pierobon, L., \& Haglind, F. (2014). Design and optimization of air bottoming cycles for waste heat recovery in offshore platforms. Applied Energy, 118, 156-165. https://doi.org/10.1016/j.apenergy.2013.12.026

\section{General rights}

Copyright and moral rights for the publications made accessible in the public portal are retained by the authors and/or other copyright owners and it is a condition of accessing publications that users recognise and abide by the legal requirements associated with these rights.

- Users may download and print one copy of any publication from the public portal for the purpose of private study or research.

- You may not further distribute the material or use it for any profit-making activity or commercial gain

- You may freely distribute the URL identifying the publication in the public portal

If you believe that this document breaches copyright please contact us providing details, and we will remove access to the work immediately and investigate your claim 


\title{
Design and optimization of air bottoming cycles for waste heat recovery in off- shore platforms
}

\author{
Leonardo Pierobon ${ }^{*}$ and Fredrik Haglind \\ Technical University of Denmark, Department of Mechanical Engineering, \\ Building 403, DK-2800 Kgs. Lyngby, Denmark
}

\begin{abstract}
This paper aims at comparing two methodologies to design an air bottoming cycle recovering the waste heat from the power generation system on the Draugen off-shore oil and gas platform. Firstly, the design is determined using the theory of the power maximization. Subsequently, the multi-objective optimization approach is employed to maximize the economic revenue, the compactness and the power production of the air bottoming cycle. The system compactness is assessed by introducing a detailed model of the shell and tube recuperator and including geometric quantities in the set of optimization variables. Findings indicate that using the power production, the volume of the recuperator and the net present value as objective functions the optimal pressure ratio (2.52) and the exhaust gas temperature $\left(178.8^{\circ} \mathrm{C}\right)$ differ from the values ( 2.80 and $145.5^{\circ} \mathrm{C}$ ) calculated using the theory of the power maximization. The highest net present value (2.8 M\$) is found for a volume of the recuperator of $128 \mathrm{~m}^{3}$. Thus, it can be concluded that the multiobjective optimization approach enables extending the theory of power maximization bridging the gap between a mere optimization of the thermodynamic cycle and the practical feasibility of a power generation system.
\end{abstract}

\footnotetext{
* Corresponding author. Tel.: +45 452541 29; fax: +45 45884325.

E-mail address: lpier@mek.dtu.dk (L. Pierobon)
} 
Keywords: Air bottoming cycle; Power Maximization; Gas Turbine; Shell and Tube Heat Exchanger; Offshore platform.

\section{Introduction}

Due to environmental concerns there is an urgent need to reduce greenhouse gas emissions and pollutants in the industrial, civil and transportation sectors. Recovering the waste heat from these activities can make a major contribution to this purpose. As reported by the Lawrence Livermore National Laboratory [1], the annual energy rejected was about $57.3 \%$ of the primary energy resources utilized in the United States in 2010. In Europe the annual recoverable industrial waste heat potential is about $140 \mathrm{TWh}$, corresponding to a $\mathrm{CO}_{2}$ reduction of about 14 Mton per year [2]. The North Sea oil and gas platforms were responsible for about 25\% of the total $\mathrm{CO}_{2}$ emissions of Norway in 2011 [3]. Since 1991 Norway levies carbon tax on petroleum, mineral fuel and natural gas with the rates based on the fuel's carbon content. As reported by the Ministry of the Environment [4], the Norwegian Government has increased the $\mathrm{CO}_{2}$ tax to $410 \mathrm{NOK}$ per ton of $\mathrm{CO}_{2}$ in 2013. Hence, the waste heat recovery in off-shore applications has become a focus area both from an environmental and an economic perspective.

In oil and gas platforms one or more redundant gas turbines are employed to support the power demand. Only a small fraction of the heat associated with the exhaust gases released by the gas turbines is recuperated. A viable solution to recover the waste heat is to place a power cycle at the bottom of the gas turbine. The air bottoming cycle $(\mathrm{ABC})$ is a technology that can be employed as an alternative to the conventional steam cycle. In fact, in off-shore platforms it may not be practical to have a steam plant due to the need for make-up water [5]. Additionally, fuel flexibility and reliability are important factors when selecting the gas turbine and, therefore, both turbine inlet and outlet temperatures are usually lower than those of state-of-art on-shore combined cycles [5]. 
The ABC was invented by Farrell (General Electric) in 1988 [6]; a year later Anderson and Farrell [7] patented the ABC for coal gasification plants. The exhaust gases from a gas turbine fired by coal gas fuel were used as the heat source. Najjar and Zaamout [8] analyzed the performance of the combined gas turbine and ABC system. The combined cycle presented an increment in thermal efficiency of about 23\% compared with the gas turbine alone. Bolland et al. [9] conducted a feasibility study for using the ABC on oil and gas platforms in the North Sea. The ABC added 10.5\%-points to the thermal efficiency of the LM2500-PE gas turbine. Total weight and package cost were estimated to be 154 metric tons and 9.4 million US\$ for a $6340.5 \mathrm{~kW}$ air bottoming cycle. Korobitsyn [10] suggested different industrial applications of the ABC. The results indicated that the technology has a payback time of three years in industries that require hot air, e.g. glass, bakery and dairy industries. In Poullikkas [11], the introduction of the ABC with two intercoolers at the bottom of the Allison 571-K gas turbine led to an increase in power from 5.9 to 7.5 MWe. More recently, Ghazikhani [12] introduced and analyzed two new cycles, e.g. the evaporating gas turbine with the ABC and the steam injection gas turbine with the ABC. Tveitaskog and Haglind [13] employed the ABC to enhance the performance of high-speed ferries; the study suggested that the thermal efficiency of the combined cycle can be increased by 8\%-points compared with the LM2500 gas turbine. Chmielniak et al. [14] carried out a technical and economic analysis of the ABC considering the heat transfer area of the recuperator and the cost of the single components. However, none of these works optimize the ABC for simultaneous consideration of the net power output, the compactness and the economic feasibility. Furthermore, the geometry of the recuperator of the $\mathrm{ABC}$ was not included in the optimization processes in any of these studies.

The present paper aims at designing and optimizing an ABC for off-shore applications. First, the theory of power maximization [15] is utilized to find the pressure ratio and the temperature of the exhaust gases that maximize the net power output of the ABC. Subsequently, the multi-objective optimization with the genetic algorithm (GA) is used to maximize the net power output and the net present value (NPV) and to minimize the volume of the recuperator. The design variables are the isentropic efficiency of the compressor and turbine, the pressure ratio and the temperature differences of the recuperator. The shell and tube heat exchanger is utilized to recuperate the waste heat exiting the gas turbine. Since the velocities inside the heat 
exchanger influence both the surface area and the pressure drop, the geometry of the shell and tube heat exchanger is also included in the optimization routine. The methodology is applied to recover the waste heat from the SGT-500 industrial gas turbine installed on the Draugen platform located in the North Sea. The economic feasibility of the combined gas turbine and $\mathrm{ABC}$ system is assessed through the net present value by assessing the total investment cost of the $\mathrm{ABC}$, the yearly income, and the cost for operation and maintenance.

The models of the $\mathrm{ABC}$ components, the equations to compute the heat transfer coefficient and the pressure drop of the shell and tube heat exchanger and the power maximization theory are described in section 2 . The case study and the multi-objective algorithm are also presented in section 2. Results of the power maximization and the multi-objective optimization are reported in section 3 and discussed in detail in section 4. Finally, the main conclusions are stated in section 5.

\section{Methodology}

\subsection{Air bottoming cycle solver}

As shown in Fig. 1, the ABC components are the turbine (AT), connected through the shaft to the electric generator (GEN), the compressor (AC) and the recuperator recovering the exhaust heat from the gas turbine. The mathematical model of each component has been developed in MATLAB ${ }^{\circledR}$ 2012a [16]. The thermodynamic and transport properties of the air and of the exhaust gases are acquired by means of the commercial software REFPROP ${ }^{\circledR} 9$ [17]. Each component is modeled at steady state conditions. 
$\mathrm{T}_{\mathrm{H}, \text { out }}$

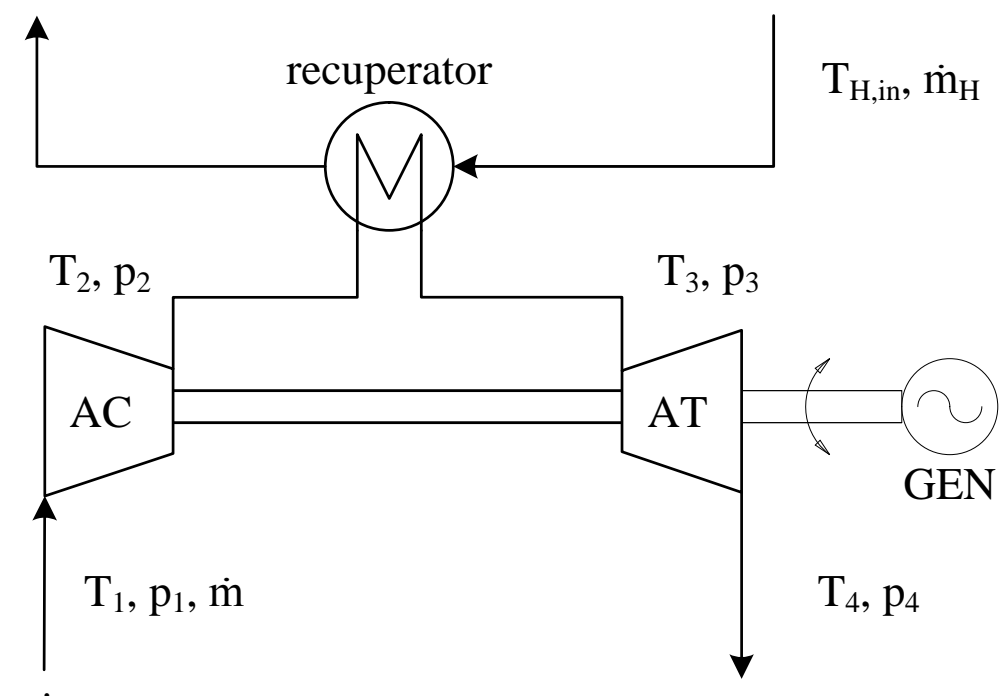

air exhaust gases

$\mathrm{T}_{\mathrm{H}, \mathrm{in}}, \dot{\mathrm{m}}_{\mathrm{H}}$

Figure 1. Air bottoming cycle layout.

The mathematical model of the ABC is solved by setting the temperature differences $\Delta T_{1}=T_{H, \text { in }}-T_{3}$ and $\Delta T_{2}$ $=T_{H, o u t}-T_{2}$ at the inlet and outlet of the recuperator. The purchase equipment cost of the compressor, $P E C_{c}$, is evaluated using Eq. (1) introduced by Valero et al. [18]:

$P E C_{c}=\left(\frac{39.5 \dot{m}}{0.9-\eta_{i s, c}}\right)\left(\frac{p_{2}}{p_{1}}\right) \ln \left(\frac{p_{2}}{p_{1}}\right)$

The purchase equipment cost of the turbine, $P E C_{t}$, is evaluated using the following equation [18]:

$P E C_{t}=\left(\frac{266.3 \dot{m}}{0.92-\eta_{i s, t}}\right)\left(\frac{p_{3}}{p_{4}}\right) \ln \left(\frac{p_{3}}{p_{4}}\right)\left[1+\exp \left(0.036 T_{3}-54.4\right)\right]$

The $P E C_{g e n}$ of the electric generator depends on the net power output $\dot{P}_{\text {net }}$ and is estimated by the following equation [19]: 
$P E C_{\text {gen }}=60 \dot{P}_{\text {net }}{ }^{0.95}$

\subsection{Shell and tube recuperator}

The recuperator exchanges heat between two gas streams, i.e. the exhaust gases exiting the gas turbine and the air compressed by the ABC compressor. Therefore, a gas to gas heat exchanger is needed. As reported by Douglas [20], two technologies are available for this application: the shell and tube heat exchanger, and the flat type heat exchanger. The shell and tube heat exchanger is selected due to its advantage of handling applications where there is a large difference in pressure between the two streams; thus, the probability of the mixing of the hot and cold fluids diminishes. The heat transfer surface area $A$ is evaluated using the basic design procedure proposed by Richardson and Peacock [21] where the governing equation for the heat transfer across a surface is

$\dot{Q}=U A F_{t} \Delta T_{l m}$

where $\dot{Q}$ is the heat rate, $U$ is the overall heat transfer coefficient, $\Delta T_{m l}$ is the logarithm mean temperature difference and $F_{t}$ is the temperature correction factor which accounts for co-current and cross flow. The correction factor in Eq. (4) is computed utilizing the method proposed by Fakheri [22]. Namely, the value of $F_{t}$ is given as a function of the inlet and outlet cold and hot side temperatures and of the number of shell passes. The overall heat transfer coefficient is calculated as the sum of five different contributors: the fluid film coefficient $h_{o}$ outside the tubes, the fluid film coefficient $h_{i}$ inside the tubes, the outside dirt coefficient (fouling factor) $h_{o d}$, the inside dirt coefficient $h_{i d}$ and the thermal conductivity of the tube wall material $\lambda_{w}$. The overall coefficient $U$ based on the outside area of the tube can be calculated as follows:

$\frac{1}{U}=\frac{1}{h_{o}}+\frac{1}{h_{o d}}+\frac{d_{0} \ln \frac{d_{0}}{d_{i}}}{2 \lambda_{w}}+\frac{d_{0}}{d_{i}} \frac{1}{h_{i d}}+\frac{d_{0}}{d_{i}} \frac{1}{h_{i}}$ 
As reported in Richardson and Peacock [21], a typical range of values of the fouling coefficient is 5000$10000 \mathrm{~W} / \mathrm{m}^{2} \mathrm{~K}$ for air and 2000-5000 W/m² K for exhaust gases. An intermediate value of $5000 \mathrm{~W} / \mathrm{m}^{2} \mathrm{~K}$ is assumed for both streams. The tube material is stainless steel with a thermal conductivity of $50 \mathrm{~W} / \mathrm{m} \mathrm{K}$.
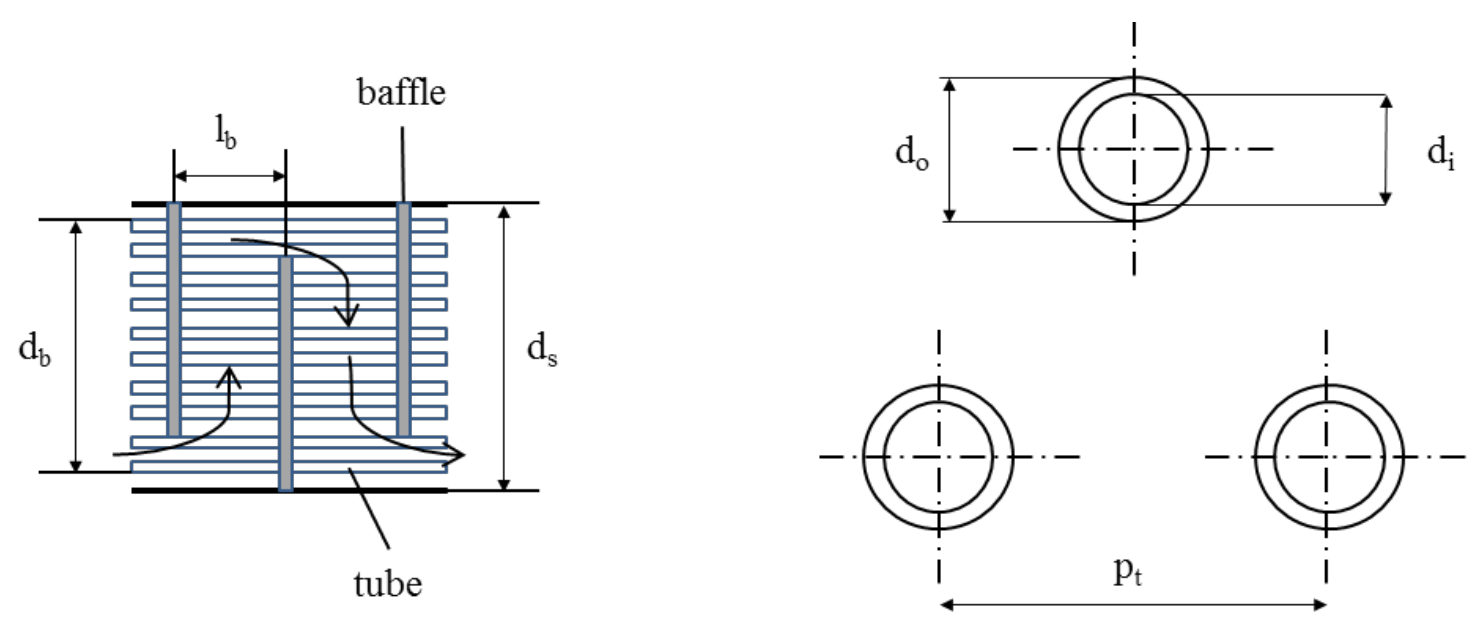

Figure 2. Shell and tube heat exchanger geometry and tube pattern.

As depicted in Fig. 2, the tubes follow a triangular pattern, which is the most common configuration [21]. The geometrical variables considered in the design are the outer diameter $d_{o}$ of the tubes, the tube length $l_{t}$, the tube thickness $t w_{t}$, the distance between the tube centers (pitch) $p_{t}$ and the baffle spacing $l_{b}$. A baffle cut of $25 \%$ is used [21]. The calculation of the heat transfer coefficients on the tube side $h_{i}$ and on the shell side $h_{o}$ in Eq. (5) is based on the experimental work carried out by Kern [23].

$h_{i}=\frac{\lambda_{t}}{d_{i}} j_{t h} \operatorname{Re}_{t} \operatorname{Pr}_{t}^{0.33}\left(\frac{\mu_{t}}{\mu_{t w}}\right)^{0.14}$

$h_{o}=\frac{\lambda_{s}}{d_{s}} j_{s h} \operatorname{Re}_{S} \operatorname{Pr}_{s}^{1 / 3}\left(\frac{\mu_{s}}{\mu_{s w}}\right)^{0.14}$

In Eqs. (6) and (7) the subscripts " $s$ " and " $t$ " refer to the shell side and the tube side, respectively. The variable $\lambda$ represents the thermal conductivity and $\mu$ the viscosity of the hot and cold stream. The viscosities 
$\mu_{t w}$ and $\mu_{s w}$ are then calculated with the temperature of the inner and of the outer wall of the tubes, respectively. The variables $R e$ and $P r$ are the Reynolds number and the Prandtl number. The quantities $j_{t h}$ and $j_{s h}$ are the heat transfer factors of the tube side and of the shell side and are evaluated as reported in Richardson and Peacock [21]. The pressure drop on the shell side $\Delta p_{s}$ are computed with the method proposed by Kern [23] and the pressure drop on the tube side $\Delta p_{t}$ with the modification introduced by Frank [24]:

$\Delta p_{s}=8 j_{s f} \frac{d_{s}}{d_{e}} \frac{l_{t}}{l_{b}}\left(\frac{\mu_{s}}{\mu_{s w}}\right)^{-0.14} \frac{\rho_{s} u_{s}^{2}}{2}$

$\Delta p_{t}=N_{t}\left[8 j_{t f} \frac{l_{t}}{d_{i}}\left(\frac{\mu_{t}}{\mu_{t w}}\right)^{-m}+2.5\right] \frac{\rho_{t} u_{t}^{2}}{2}$

where $u_{t}$ and $u_{s}$ are the velocity across the shell and inside the tubes, $N_{t}$ is the number of tubes, $d_{s}$ is the shell diameter, $d_{e}$ is the equivalent diameter on the shell side and $m$ is a coefficient equal to 0.25 for laminar flow ( $R e<2100)$ and 0.14 for turbulent flow $(R e>2100)$. The quantities $j_{t f}$ and $j_{s f}$ are the friction factors of the tube side and of the shell side and are evaluated as reported in Richardson and Peacock [21]. The geometry of the recuperator can be calculated following the iterative design procedure described in detail in Richardson and Peacock [21]. The design process can be summarized in the following steps:

a) Calculation of the heat rate $\dot{Q}$ using Eq. (4).

b) Initial guess for the value of the overall heat transfer coefficient $U$ and preliminary calculation of the heat transfer area $A$

c) Computation of the heat exchanger geometry given the tube length $l_{t}$, outer diameter $d_{o}$, tube pitch $p_{t}$, tube thickness $t w_{t}$ and baffle spacing $l_{b}$

d) Computation of the fluid velocities on the tube and shell side and of the individual fluid film coefficients $h_{i}$ and $h_{o}$ (see Eqs. (6) and (7))

e) Calculation of the overall heat transfer coefficient $U$ and comparison with the initial trial value $U$ 
f) Re-iteration of the procedure from step b) to step e) until the difference between the two latest $U$ values is lower than a certain value

g) Calculation of the pressure losses on the tube side $\Delta p_{t}$ and on the shell side $\Delta p_{s}$ (see Eqs. (8) and (9))

Detailed equations on how to derive the quantities describing the geometry of shell and tube heat exchangers (e.g. shell diameter, number of tubes and the equivalent diameter of the shell) for given tube length, outer diameter, tube thickness, tube pitch and baffle spacing are reported in Richardson and Peacock [21]. The design procedure implemented in MATLAB $^{\circledR}$ 2012a has been validated using an example outlined in Richardson and Peacock [21], comprising the design of a heat exchanger to sub-cool condensate from a methanol condenser with the use of liquid water as coolant. The results indicate differences of less than $1 \%$ in overall heat transfer coefficients and pressure drops between the models derived here and the results provided in Richardson and Peacock [21].

The recuperator is assumed to be a cylinder of diameter $d_{s}$ (shell diameter) and height $l_{t}$. Equation (10) enables to compute the volume of the recuperator; a correction factor of 1.2 is applied to consider the space required by the inlet and outlet ducts.

$$
V_{\text {rec }}=1.2 \frac{\pi}{4} d_{s}{ }^{2} l_{t}
$$

The purchase equipment cost of the recuperator $P E C_{\text {rec }}$ relates to the heat transfer area $A$ as reported in Eq. (11). The expression was suggested by Hall [26] for stainless steel shell and tube heat exchangers.

$P E C_{\text {rec }}=10000+324 A^{0.91}$

\subsection{Theory of power maximization}


The main scope of an air bottoming cycle placed at the bottom of a gas turbine is to convert most of the exhaust heat into electric power, i.e. to maximize the net power output. Considering a reversible $\mathrm{ABC}$ with no heat losses to the environment, the optimal pressure ratio $r_{c}$ and exhaust temperature $T_{H, \text { out }}$ can be evaluated using the theory outlined in Bejan [15] and Leff [27]. If the irreversibilities associated with the compression and expansion processes and with the heat transfer process in the recuperator are included, the optimal pressure ratio and exhaust temperature can be expressed as follows:

$r_{C}=\frac{p_{2}}{p_{1}}=\frac{\left(\frac{T_{H, i n}-\Delta T_{1}}{T_{1}} \eta_{i s, c} \eta_{i s, t}\right)^{\frac{k}{2(k-1)}}}{\sqrt{p_{3} / p_{2}}}$

$T_{H, \text { out }}=\Delta T_{2}+T_{1}\left(1-1 / \eta_{i s, c}\right)+\sqrt{\frac{\left(T_{H, i n}-\Delta T_{1}\right) T_{1} \eta_{i s, t}}{\eta_{i s, c}}} /\left(\frac{p_{3}}{p_{2}}\right)^{\frac{k-1}{2 k}}$

Equations (12) and (13) provide the pressure ratio and the temperature of the exhaust gases that maximize the net power output of the $\mathrm{ABC}$ for given compressor and turbine isentropic efficiencies, the inlet and outlet temperature difference and the pressure drop of the recuperator. Generally, when comparing turbomachineries of different pressure ratios, it is advisable to work with constant polytropic efficiency rather than an isentropic efficiency. In this paper, however, isentropic efficiencies are employed, because doing so enables us to derive analytical expressions for the exhaust gas temperature and the optimal pressure ratio (see Eqs. (12) and (13)) and to evaluate directly the cost of the air compressor and turbine (see Eqs. (1) and (2)). For reasons of consistency, the same approach is utilized in the multi-objective optimization. The implications on the results of using isentropic efficiencies rather than polytropic efficiencies are quantified in section 4. Table 1 lists the design variables assumed to solve the ABC using the theory of power maximization.

Table 1. Design point parameters assumed for the air bottoming cycle. 


\begin{tabular}{ll}
\hline Variable & Value \\
\hline Compressor isentropic efficiency $\eta_{i s, c}$ & 0.89 \\
Turbine isentropic efficiency $\eta_{i s, t}$ & 0.9 \\
Recuperator relative pressure drop (tube side) $\Delta p_{t}$ & $2 \%$ \\
Recuperator outlet temperature difference $\Delta T_{2}$ & $20{ }^{\circ} \mathrm{C}$ \\
Generator electric efficiency $\eta_{e l}$ & 0.98 \\
\hline
\end{tabular}

\subsection{Multi-objective optimization}

The theory of power maximization enables us to find the optimal design of the air bottoming cycle based on the net power output. However, the methodology does not include the economic feasibility of the ABC as waste heat recovery unit. Furthermore, in many applications, e.g. on off-shore platforms, the compactness of the unit is a crucial concern. These issues are addressed by employing a multi-objective optimization which optimizes simultaneously two or more functions by means of a specific algorithm. The user defines one or more objective functions, sets the number of variables and the upper and lower bounds, and subsequently the routine starts to evaluate the objective functions. Compared to gradient-based methods (e.g. Steepest Descent Method [28]), the genetic algorithm (GA) [29] is used as it avoids the calculation of derivatives.

Furthermore, Kocer and Arora [30] found that compared to the simulating annealing method and the enumeration method, the GA requires less computational time and has a higher tendency to converge to global optima. The population and generation size are set to 1000 and 200 while the crossover fraction and migration factor are fixed to 0.8 and 0.2 . These numerical values are selected by means of a sensitivity analysis in order to ensure the repeatability of the solution when different simulations are performed and to avoid that the method stops on local minima/maxima. The solution of a multi-objective optimization is not a single global solution, but a set of points that all fit the so-called "Pareto optimality". Hence, the routine provides a Pareto front (curve) with a number of dimensions equal to the size of the array of the objective functions $J$ : 
$J=\left[\dot{P}_{n e t}, V_{r e c}, N P V\right]$

As expressed in Eq. (14), the net power output of the ABC, the volume of the recuperator and the net present value are selected as objective functions. According to Bejan et al. [31], the $N P V$ can be calculated considering the equipment lifespan $n$, the interest factor $q$, the total capital investment $I_{\text {TOT }}$ and the annual income $R_{i}$ :

$N P V=\sum_{i=1}^{n} \frac{R_{i}}{(1+q)^{i}}-I_{T O T}$

The array of the optimization variables $X$ considered in this work can be expressed as follows:

$X=\left[\eta_{i s, c}, \eta_{i s, t}, \Delta T_{1}, \Delta T_{2}, r_{c}, d_{o}, l_{t}, t w_{t}, l_{b}, p_{t}\right]$

where $\Delta T_{1}$ and $\Delta T_{2}$ are the temperature differences at the inlet and outlet of the recuperator. In order to find a compromise between economy and performance of the compressor and turbine, the isentropic efficiencies are included in the set of optimization variables. In fact, high isentropic efficiencies imply lower thermodynamic irreversibilities (higher net power output) at the price of higher investment costs (see Eqs. (1) and (2)). Hence, using the set of objective functions defined in Eq. (14), the optimal quantities can be determined. The lower and upper bounds for each variable involved in the optimization process are listed in Table 2.

Table 2. Lower and upper bounds specified for the variables included in the multi-objective optimization (bounds for the geometry of the heat exchanger are taken from Richardson and Peacock [21]).

Parameter $\quad$ Lower bound $\quad$ Upper bound




\begin{tabular}{lll} 
Recuperator inlet temperature difference $\Delta T_{1}$ & $20{ }^{\circ} \mathrm{C}$ & $70{ }^{\circ} \mathrm{C}$ \\
Recuperator outlet temperature difference $\Delta T_{2}$ & $20{ }^{\circ} \mathrm{C}$ & $70{ }^{\circ} \mathrm{C}$ \\
Pressure ratio $p_{2} / p_{1}$ & 1.5 & 4.5 \\
Compressor isentropic efficiency $\eta_{i s, c}$ & 0.8 & 0.9 \\
Turbine isentropic efficiency $\eta_{i s, t}$ & 0.8 & 0.92 \\
Tube outer diameter $d_{o}$ & $16 \mathrm{~mm}$ & $50 \mathrm{~mm}$ \\
Tube length $l_{t}$ & $1.83 \mathrm{~m}$ & $7.32 \mathrm{~m}$ \\
Tube thickness $t w_{t}$ & $1.2 \mathrm{~mm}$ & $3.2 \mathrm{~mm}$ \\
Baffle spacing $l_{b}$ & $0.2 d_{s}$ & $1.0 d_{s}$ \\
Tube pitch $p_{t}$ & $1.15 d_{0}$ & $2.25 d_{0}$ \\
\hline
\end{tabular}

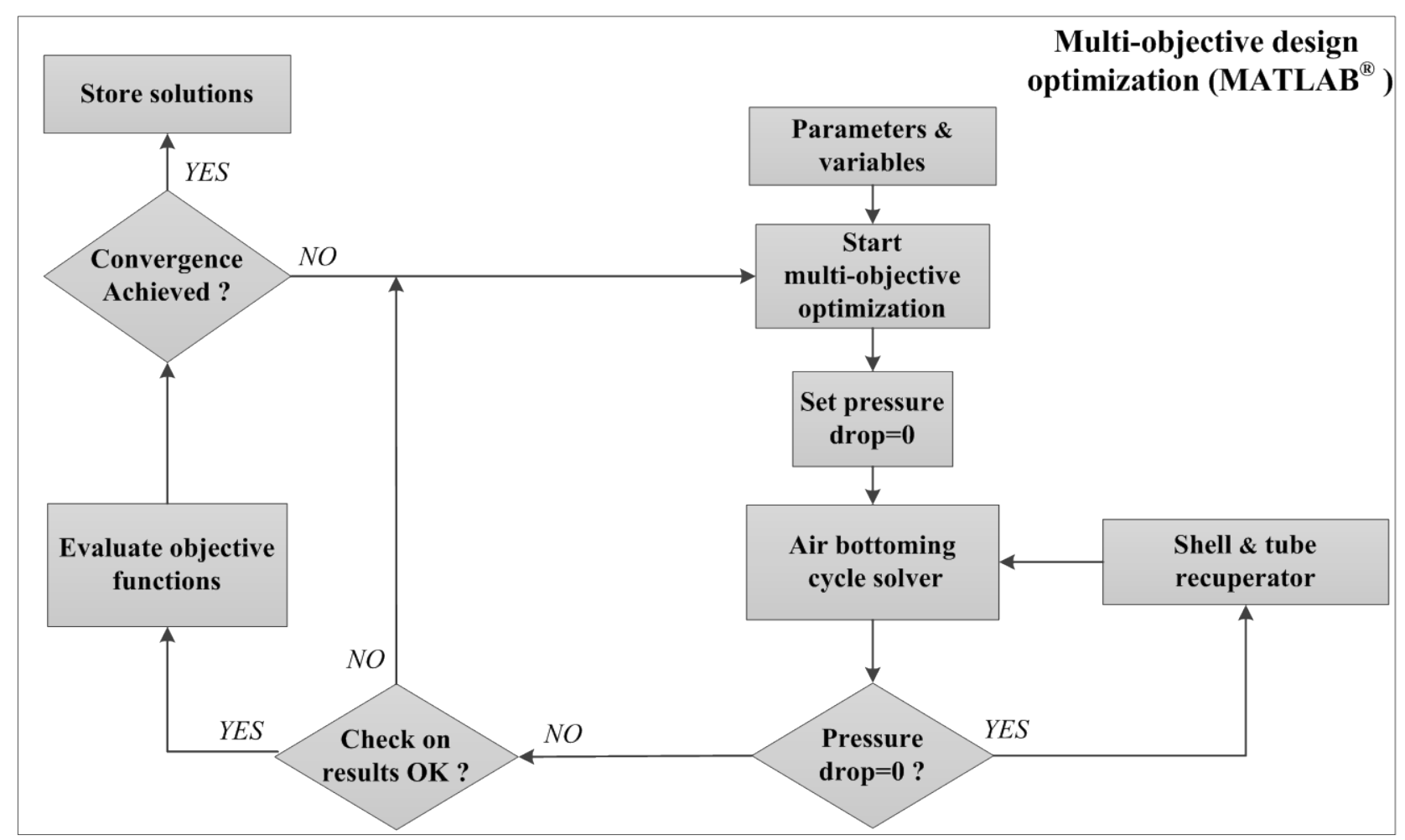

Figure 3. Structure of the multi-objective algorithm. The optimization routine involves the air bottoming cycle solver, the shell and tube designer, and the evaluation of the objective functions. 
The graphic representation of the complete optimization algorithm is depicted in Fig. 3. Firstly, the GA generates the initial population using pseudo random values for the optimization variables respecting the lower and upper bounds. The variables are then passed to the ABC solver that calculates the net power output and the temperature, and pressure and enthalpy in the four nodes of the cycle (see Fig. 1).

At this stage the pressure drop in the recuperator is set to 0 . Subsequently, the gas to gas shell and tube heat exchanger is designed by acquiring the inlet and outlet temperatures and pressures, the mass flows on each side and the optimization variables related the geometric of the recuperator (i.e. the outer diameter, the length and the thickness of the tubes, the baffle spacing and the tube pitch). The shell and tube designer computes the heat transfer area based on the well-established design procedure described in details in Richardson and Peacock [21] and summarized in section 2.2. Moreover, it is verified that the velocities in the tube and in the shell are within the admissible range of gaseous fluids (5-30 m/s [21]). The shell and tube designer calculates the volume and the pressure drop on each side of the recuperator. Subsequently, the ABC solver re-calculates the net power output including the pressure drop of the recuperator. The procedure continues with the calculation of the investment cost and the net present value. The routine terminates when the maximum number of generations is reached or when the average change of the solution is lower than the specified tolerance $\left(10^{-3}\right)$; if this is not the case, a new calculation starts.

\subsection{Case study}

The results of the power maximization theory and the multi-objective optimization are compared for designing a waste heat recovery unit on the Draugen off-shore platform, located 150 km from Kristiansund, in the Norwegian Sea. The platform, operated by A/S Norske Shell, produces both oil and gas. The oil is stored in storage cells at the bottom of the sea and is exported via a shuttle tanker. The gas flows through the Åsgard gas pipeline to Kårstø where it is sold to the market. Three Siemens SGT-500 gas turbines are utilized on the platform to provide the normal total electric load, equal to $19 \mathrm{MW}$. The power demand is increased up to $25 \mathrm{MW}$ (peak load) during seawater lifting, water injection, and oil export. In order to enhance the reliability and to diminish the risk of failure of the power generation system, two turbines run at 
a time covering $50 \%$ of the load each, while the third is kept on stand-by, allowing for maintenance work. Despite the low performance, this strategy ensures the necessary reserve power for peak loads, and the safe operation of the engines. The engine model is the C-version launched in the beginning of the 1980s. Table 3 reports the design point specifications of the engine [5].

Table 3. Design point specifications for the Siemens SGT-500 twin-spool gas turbine [5].

\begin{tabular}{ll}
\hline Model & Siemens SGT-500 \\
\hline Turbine inlet temperature & $850{ }^{\circ} \mathrm{C}$ \\
Exhaust gas temperature & $376{ }^{\circ} \mathrm{C}$ \\
Exhaust gas mass flow & $93.5 \mathrm{~kg} / \mathrm{s}$ \\
Net power output & $17.014 \mathrm{MW}$ \\
Heat rate & $11312 \mathrm{~kJ} / \mathrm{kWh}$ \\
Fuel & Naphtha, crude oil, heavy fuel oil, \\
& bio oil, natural gas, syngas \\
\hline
\end{tabular}

As can be noted in Fig. 4, the low pressure compressor (LPC) and the high pressure compressor (HPC) are connected to the low pressure turbine (LPT) and to the high pressure turbine (HPT) respectively. In addition, the gas turbine features a power turbine (PT). Figure 4 indicates that the compressed air flows on the tube side of the recuperator, since high pressure tubes are cheaper than high pressure shells [21]. 


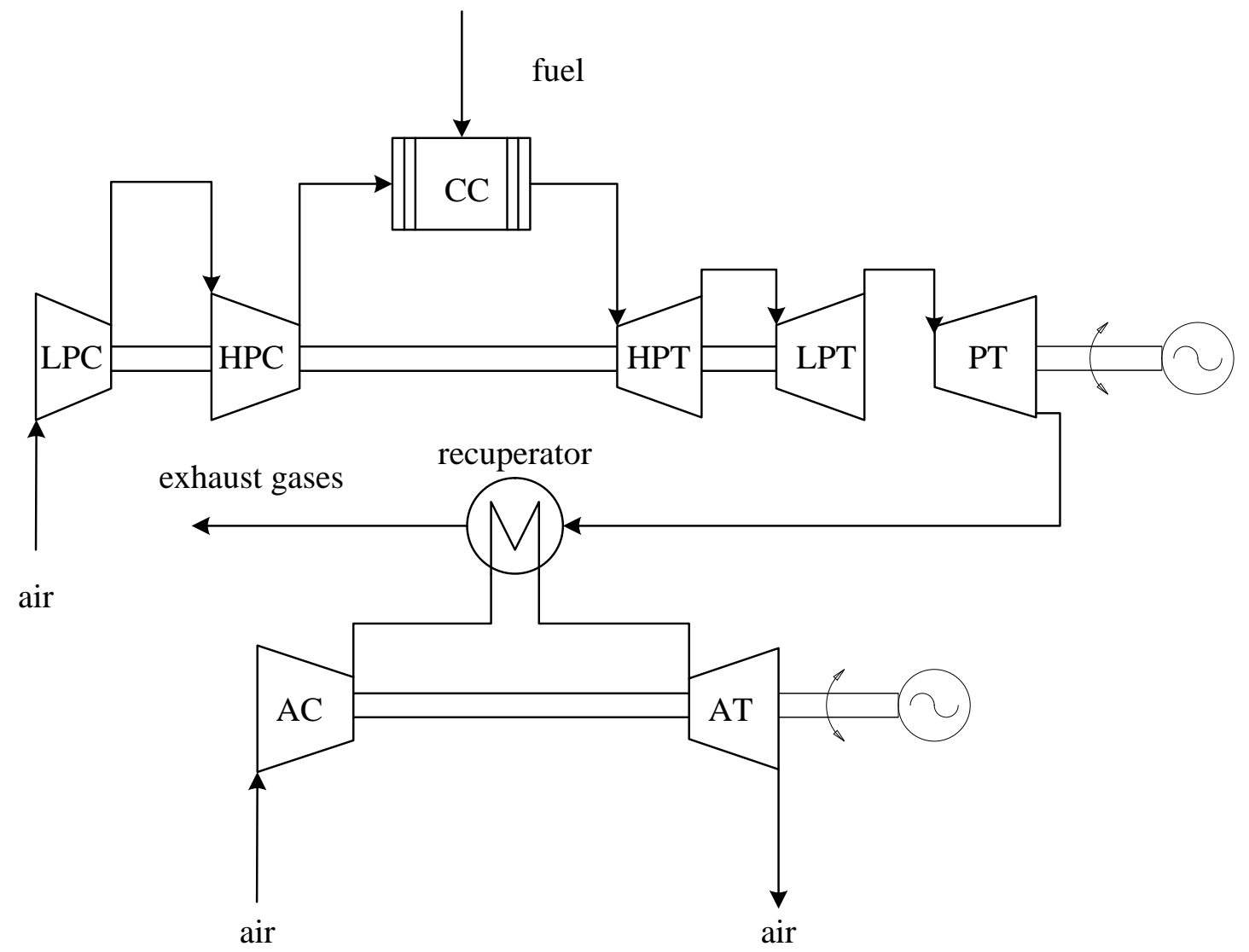

Figure 4. Combined cycle layout including one SGT-500 twin-spool gas turbine and the air bottoming cycle.

$N P V=\sum_{i=1}^{n} \frac{M h u\left(R_{C H 4}+R_{C O 2}\right)}{(1+q)^{i}}-I_{T O T}$

As expressed in Eq. (17), the evaluation of the net present value requires the calculation of the total investment cost $I_{T O T}$ and of the two incomes $R_{\mathrm{CO} 2}$ and $R_{\mathrm{CH} 4}$. The first relates to the $\mathrm{CO}_{2}$ taxes and the second to the fuel savings. The detailed equations utilized to assess the two incomes and the total investment cost (see Eq. (17)) can be retrieved from Pierobon et al. [25]. The maintenance factor $M$ and the utilization factor hu are set to 0.9 and $7000 \mathrm{hr} /$ year. An equipment lifespan $n$ of 20 years and an interest factor $q$ of $10 \%$ are assumed. Based on the press release of the Ministry of the Environment [4], the carbon tax is set to 410 NOK per ton of $\mathrm{CO}_{2}$. The $\mathrm{CO}_{2}$ emissions of the SGT-500 are set to $2.75 \mathrm{~kg}_{\mathrm{CO} 2} / \mathrm{kg}_{\mathrm{f}}$ [32] while the fuel consumption is calculated depending on the load using the data provided by the gas turbine manufacturer. In the case that the power output of the combined system (one gas turbine and the air bottoming cycle) is lower than $19 \mathrm{MW}$ 
the system operates at $100 \%$ and a second gas turbine provides the remaining power. On the contrary, the combined cycle provides alone the total power demand operating at part-load. For the latter case calculations show that the combined cycle load is always higher than 95\%; thus, a constant thermal efficiency for the combined cycle is assumed. Hence, the savings of $\mathrm{CO}_{2}$ emissions and of fuel consumption are calculated with respect to the existing power generation system. A constant $\mathrm{CO}_{2}$ emission (per kg of fuel) is assumed from the gas turbines when the load is reduced.

\section{Results and discussion}

In this section the results obtained through the theory of power maximization are presented in section 3.1. Subsequently, in section 3.2, the outputs of the multi-objective optimization considering both the volume of the recuperator and the net present value are listed.

\subsection{Maximum power design}

The theory of power maximization, outlined in section 2.3, allows obtaining the full profile (mass flow and outlet temperature) of the heat source and the ABC pressure ratio that maximizes the net power output. The ISO conditions for the ambient pressure and temperature (1.013 bar and $288.15 \mathrm{~K})$ are considered. The pressure drop on the shell side of the recuperator $\Delta p_{s}$ is neglected.

Figure 5 depicts the net power output versus the pressure ratio of the air compressor for different turbine inlet temperatures, i.e. inlet temperature differences of the recuperator $\Delta T_{1}$. The dots in the figure represent the values calculated using Eq. (12) and setting the isentropic exponent $k$ equal to 1.37. 


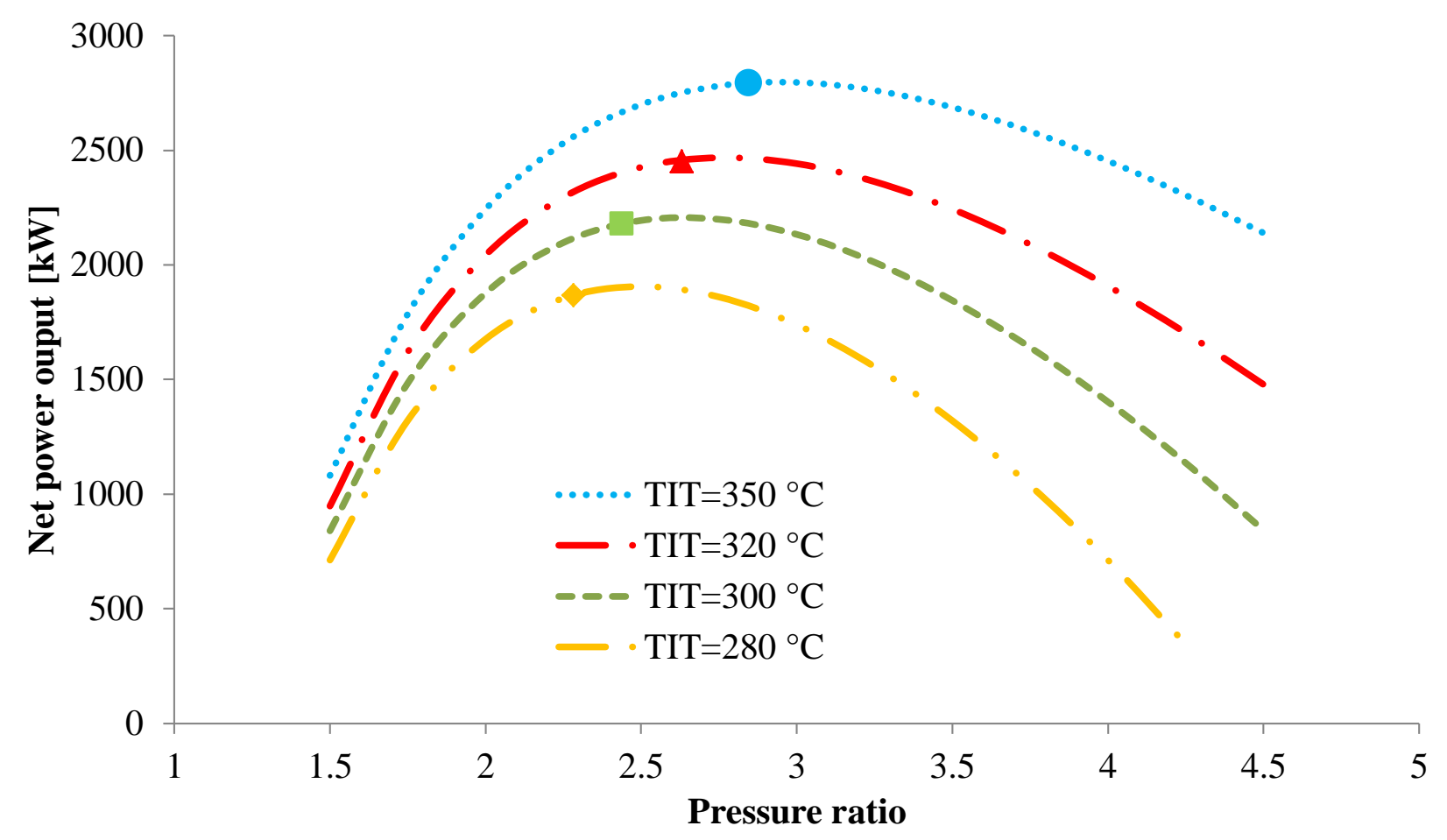

Figure 5. Net power output versus pressure ratio for different turbine inlet temperatures (TITs). The dots are calculated applying Eq. (12).

Equation (12) gives an optimal pressure ratio of 2.80 and a net power of $2793 \mathrm{~kW}$ which corresponds to a thermal efficiency of $12.1 \%$. At the lowest turbine inlet temperature $\left(280^{\circ} \mathrm{C}\right)$, the maximum electric production is $1867 \mathrm{~kW}$ at a pressure ratio of 2.28. Figure 6 relates the exhaust temperature $T_{H, \text { out }}$ to the pressure ratio obtained with the ABC solver (continuous line) and using Eqs. (12) and (13) (dots). The curve is the same at the different inlet temperature differences of the recuperator. However, the temperature of the exhaust gases exiting the recuperator corresponding to the maximum power differs for each case ranging from $138.2^{\circ} \mathrm{C}$ down to $117.5^{\circ} \mathrm{C}$. Furthermore, it can be observed that the optimal pressure ratio and exhaust gas temperature calculated using Eqs. (12) and (13) differ from the curve obtained by using the ABC solver (section 2.1). Namely, Fig. 6 shows a highest relative deviation of 5.3\% on the calculation of the exhaust gas temperature at the optimal pressure ratio. It should also be noticed that the dots in Fig. 5 do not meet exactly the maximum of the curves. The reasons for the deviations are that, in order to derive Eqs. (12) and (13), air is treated as an ideal gas with a constant isentropic exponent $\mathrm{k}$. 


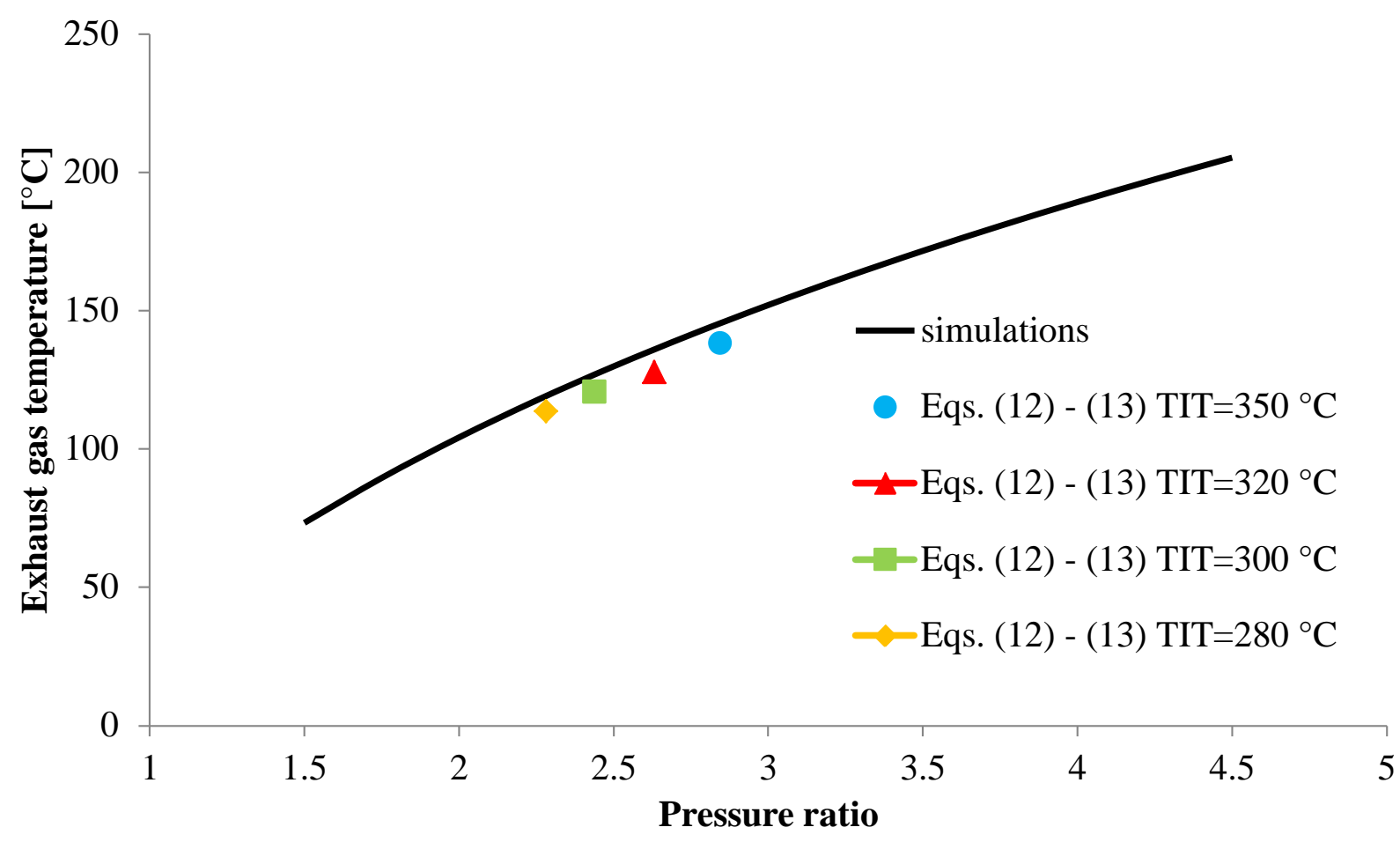

Figure 6. Exhaust gas temperature versus pressure ratio. The dots are calculated for different turbine inlet temperatures (TITs) applying Eqs. (12) and (13) and using the parameters listed in Table 1.

The net power output and the thermal efficiency of the ABC are plotted in Fig. 7 for different inlet temperature differences of the recuperator. Each curve presents a variation in the pressure ratio between 1.5 and 4.5 bar (see the blue line in Fig. 7). It can be noted that the pressure ratios giving the maximum net power output and the highest thermal efficiency are different. For example, at a turbine inlet temperature of $350{ }^{\circ} \mathrm{C}$, the pressure ratios giving the highest net power output and the best thermal efficiency are around 2.80 and 3.75 , respectively. At the lowest examined temperature $\left(280^{\circ} \mathrm{C}\right)$ the two maxima are located at a pressure ratio of 2.28 (power output) and 2.75 (thermal efficiency). Hence, the design of the ABC reported in Table 4 can be proposed for recuperating the waste heat from the SGT-500 targeting the maximum net power output. 


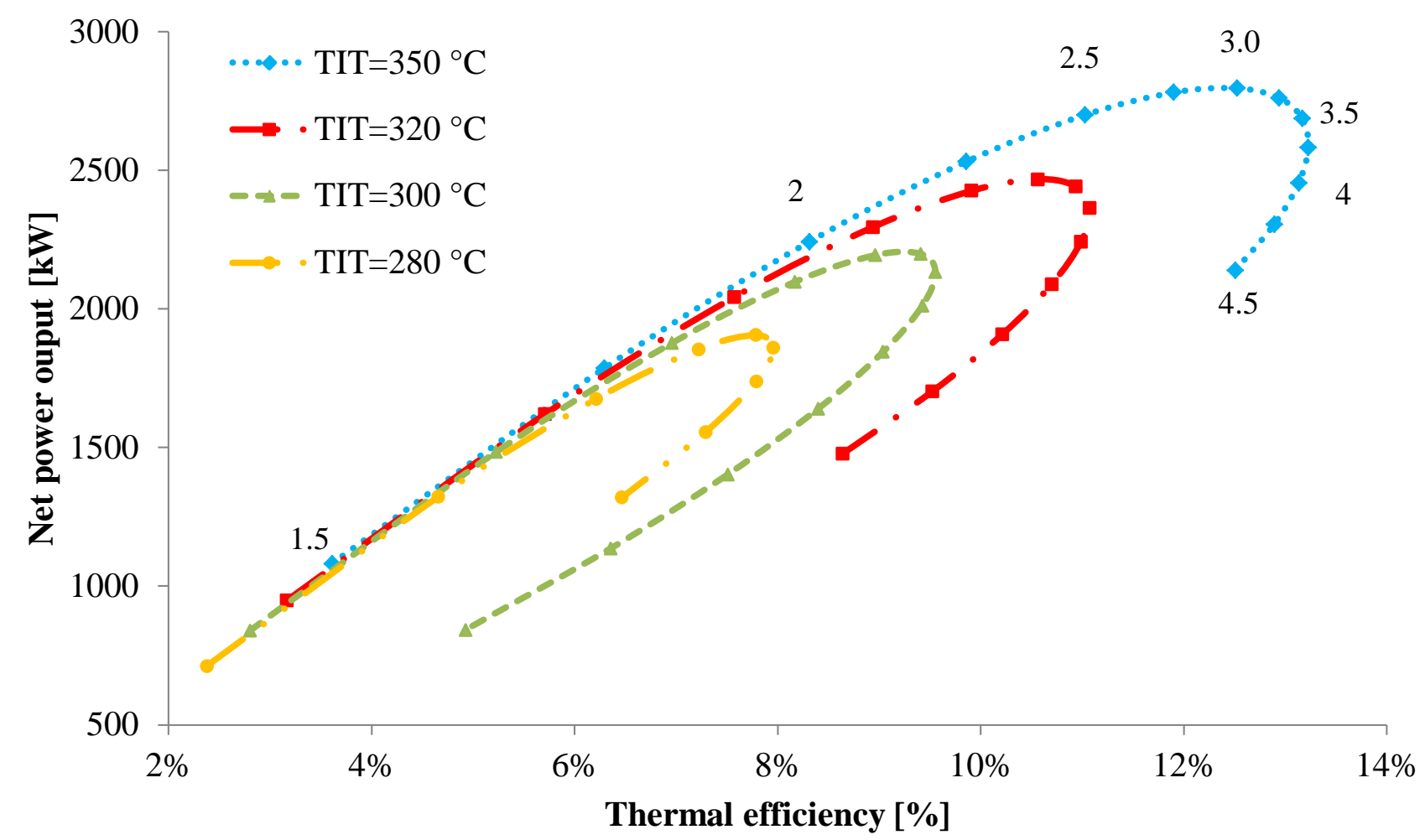

Figure 7. Net power output versus ABC thermal efficiency for different turbine inlet temperatures (TITs).

The corresponding pressure ratios for the curve with the highest turbine inlet temperature (blue line) are also reported.

Table 4. Design point results for the air bottoming cycle.

\begin{tabular}{ll}
\hline Variable & Value \\
\hline & \\
Pressure ratio $p_{2} / p_{1}$ & 2.80 \\
Mass flow $\dot{m}$ & $98.4 \mathrm{~kg} / \mathrm{s}$ \\
Exhaust temperature $T_{H, \text { out }}$ & $145.5^{\circ} \mathrm{C}$ \\
Recuperator inlet temperature difference $\Delta T_{1}$ & $26{ }^{\circ} \mathrm{C}$ \\
Heat rate (recuperator) $\dot{Q}$ & $22970 \mathrm{~kW}$ \\
Net power output $P_{e l}$ & $2793 \mathrm{~kW}$ \\
Thermal efficiency $\eta_{t h}$ & $12.1 \%$ \\
\end{tabular}


To be noticed that the theory of power maximization does not enable selecting an optimal design of the recuperator, but it only allows the calculation of the pressure ratio and of the exhaust gas temperature that maximizes the power output. Theoretically, no limits on the isentropic efficiency of the compressor and the turbine and on the inlet and outlet temperature difference of the recuperator are encountered. Furthermore, a constant pressure relative pressure drop (2\%) in the recuperator is assumed. Therefore, it can be stated that the theory of power maximization is not sufficient for tailoring the $A B C$ to recover the waste heat on offshore installation. Thus, the theory needs to be extended by including in the objective functions the compactness of the system (i.e. the volume of the recuperator) and economic indicators (e.g. net present value and pay-back time).

\subsection{Multi-objective optimization design}

The multi-objective optimization gives 350 possible solutions, i.e. number of points in the 3-dimensional Pareto front. Figure 8 relates the volume of the recuperator versus the net power output. The Pareto front ranges from a volume of $69.7 \mathrm{~m}^{3}$ up to $207.7 \mathrm{~m}^{3}$. The higher the volume, the greater is the electricity production which varies from $1436 \mathrm{~kW}$ up to $2543 \mathrm{~kW}$. 


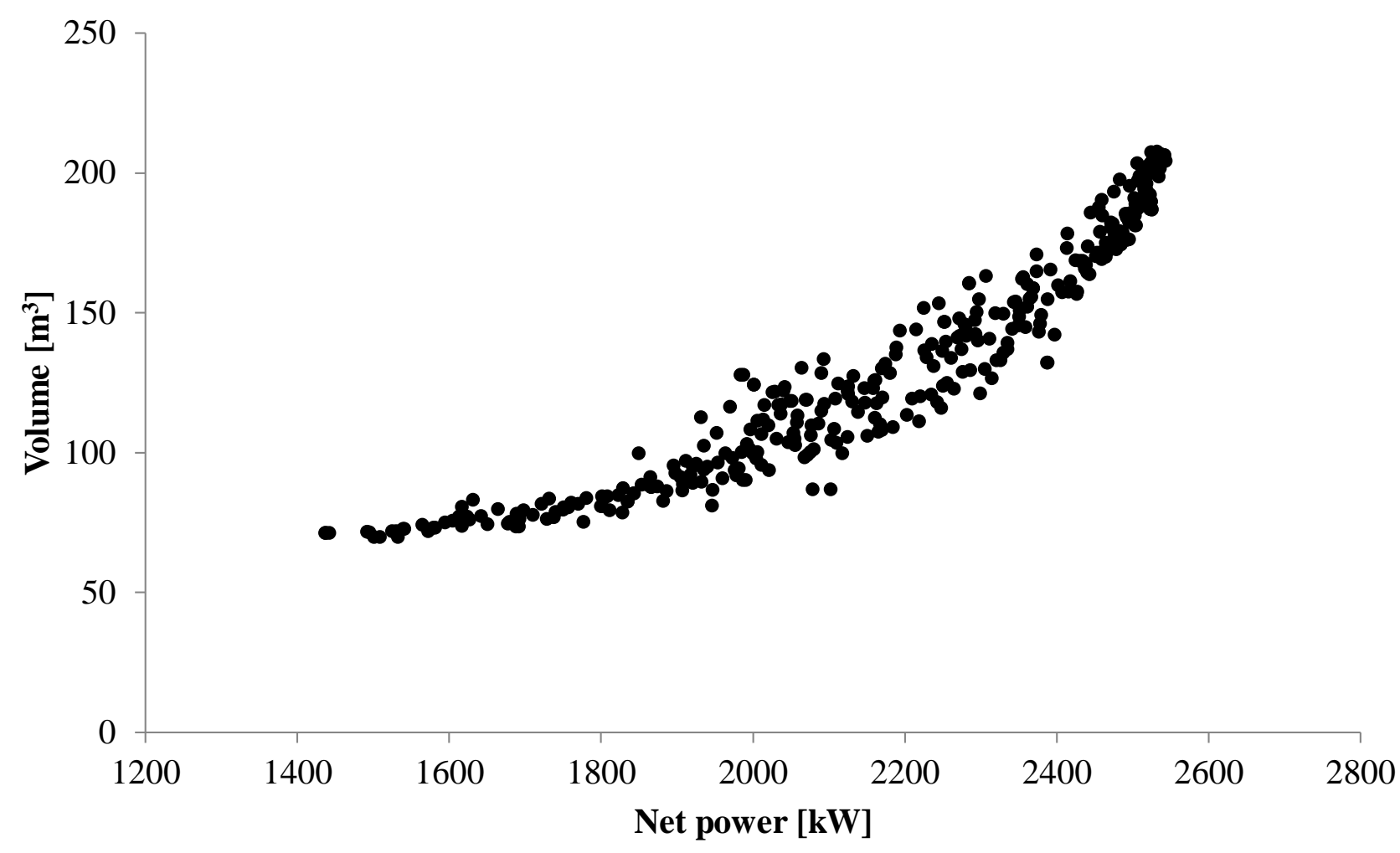

Figure 8. Pareto front obtained through the multi-objective optimization representing the total volume of the recuperator versus net power output.

Figure 9 depicts the net present value versus the volume of the recuperator. It can be seen that the net present value presents a steep increment between 69.7 and $127.7 \mathrm{~m}^{3}$, and it reaches a maximum of $2.80 \mathrm{M} \$$. Subsequently, the NPV drops, with a similar gradient, down to zero at a recuperator volume of $204.3 \mathrm{~m}^{3}$. 


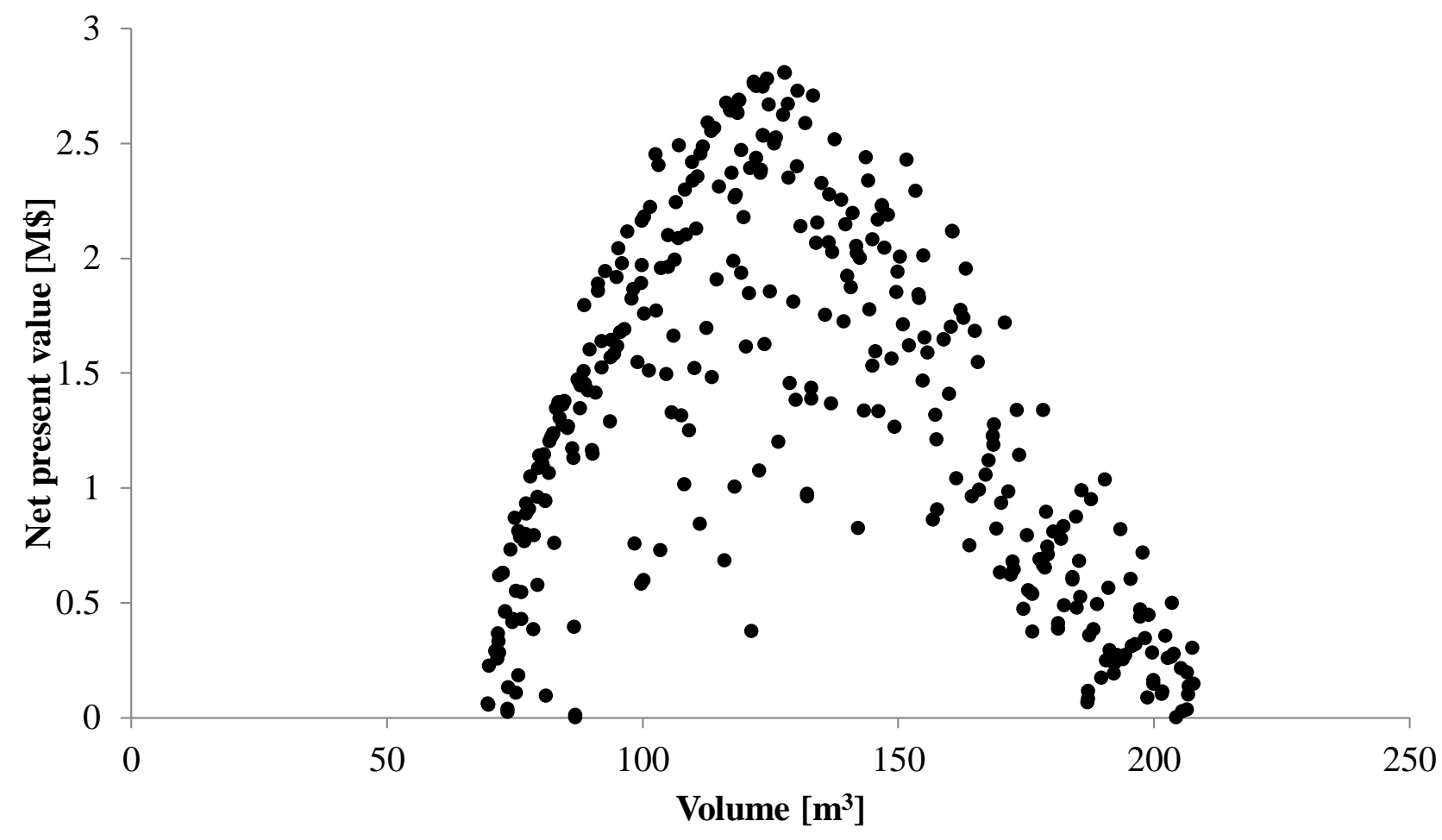

Figure 9. Pareto front obtained through the multi-objective optimization representing the net present value versus the volume of the recuperator.

As concerns the optimization variables, the results indicate that the isentropic efficiencies of the compressor and of the turbine are within the range of $0.879-0.889$ and of $0.879-0.903$, respectively. The pressure ratio of the compressor is 2.67 on average. The inlet and outlet temperature differences of the recuperator are 41.9 ${ }^{\circ} \mathrm{C}$ and $61.0^{\circ} \mathrm{C}$ on average. The length and the diameter of the tubes vary between 4.76 and $5.75 \mathrm{~m}$ and between 26.9 and $41.0 \mathrm{~mm}$. The tubes are on average $1.53 \mathrm{~mm}$ thick. The ranges of solutions for the tube pitch and the baffle spacing are 1.32-1.62 and 0.37-0.51, respectively. Furthermore, Fig. 10 shows the overall heat transfer coefficient versus the volume of the recuperator. It can be noticed that the heat transfer coefficient varies from 46.2 to $69.0 \mathrm{~W} / \mathrm{m}^{2} \mathrm{~K}$ and that it increases linearly with a decrease in volume. 


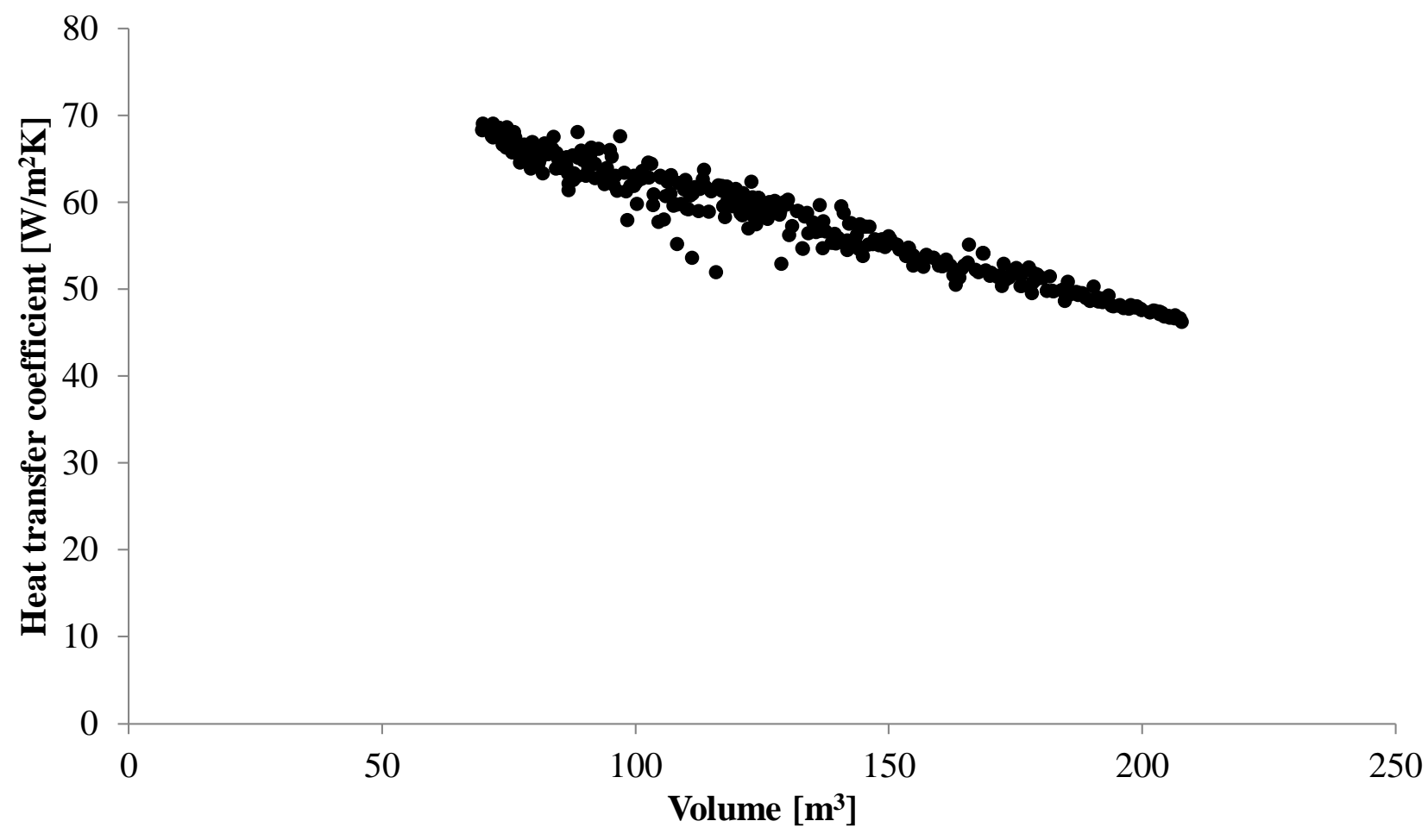

Figure 10. Overall heat transfer coefficient versus the volume of the recuperator for each point of the Pareto front.

Figures 8 and 9 suggest designing the air bottoming cycle to operate where the net present value reaches the maximum (2.80 M\$). This occurs at a volume of $127.7 \mathrm{~m}^{3}$, corresponding to a net power output of $1983 \mathrm{~kW}$. However, compactness may represent the major constraint: thus, if a lower volume is required, the optimum design falls at the specified volume. For this specific case it is not economically feasible to implement the $\mathrm{ABC}$ when the available volume is lower than $69.7 \mathrm{~m}^{3}$. Table 5 lists the geometry, the pressure drop of the recuperator and the investment cost of each of the $\mathrm{ABC}$ components.

Table 5. Geometry, investment cost and volume for the proposed optimal solution selected from the Pareto front. 


\begin{tabular}{|c|c|}
\hline Variable & Value \\
\hline \multicolumn{2}{|l|}{ Air bottoming cycle } \\
\hline Thermal efficiency & $10.0 \%$ \\
\hline Net power output & $1983 \mathrm{~kW}$ \\
\hline Net present value & $2.80 \mathrm{M} \$$ \\
\hline Purchase cost & $2.02 \mathrm{M} \$$ \\
\hline \multicolumn{2}{|l|}{ Compressor } \\
\hline Inlet mass flow & $87.5 \mathrm{~kg} / \mathrm{s}$ \\
\hline Pressure ratio & 2.52 \\
\hline Compressor isentropic efficiency & 0.879 \\
\hline Purchase cost & $0.25 \mathrm{M} \$$ \\
\hline \multicolumn{2}{|l|}{ Turbine } \\
\hline Pressure ratio & 2.46 \\
\hline Turbine isentropic efficiency & 0.883 \\
\hline Purchase cost & $0.57 \mathrm{M} \$$ \\
\hline \multicolumn{2}{|l|}{ Recuperator } \\
\hline Heat rate & $19711 \mathrm{~kW}$ \\
\hline Recuperator inlet temperature difference & $43.6^{\circ} \mathrm{C}$ \\
\hline Recuperator outlet temperature difference & $64.7^{\circ} \mathrm{C}$ \\
\hline Volume & $127.7 \mathrm{~m}^{3}$ \\
\hline Pressure drop tube side & $5.85 \mathrm{kPa}$ \\
\hline Heat transfer coefficient & $58.7 \mathrm{~W} / \mathrm{m}^{2} \mathrm{~K}$ \\
\hline Tube diameter & $38.2 \mathrm{~mm}$ \\
\hline Tube thickness & $1.42 \mathrm{~mm}$ \\
\hline Tube length & $5.09 \mathrm{~m}$ \\
\hline
\end{tabular}




\begin{tabular}{lc}
\hline Pitch ratio & $1.35 d_{0}$ \\
Baffle spacing & $2.19 \mathrm{~m}$ \\
Purchase cost & $1.12 \mathrm{M} \$$ \\
Electric generator & \\
Purchase cost & $0.08 \mathrm{M} \$$ \\
\hline
\end{tabular}

The pressure ratio and turbine inlet temperature giving the highest economic revenue $\left(2.52\right.$ and $332.4{ }^{\circ} \mathrm{C}$, respectively) are lower than the values calculated with the theory of power maximization. Consequently, the net power output and the thermal efficiency of the ABC are decreased by around $800 \mathrm{~kW}$ and 2.0\%-points respectively. The main reason is the different design of the recuperator. In fact, due to the low heat transfer coefficient $58.7 \mathrm{~W} / \mathrm{m}^{2} \mathrm{~K}$, the volume and the purchase cost become large $\left(127.7 \mathrm{~m}^{3}\right.$ and $1.12 \mathrm{M} \$$, respectively). Hence, higher inlet and outlet temperature differences $\left(43.6^{\circ} \mathrm{C}\right.$ and $64.7^{\circ} \mathrm{C}$, respectively) are needed for the recuperator. On the other hand, the pressure drops on the tube side of the recuperator are low (0.05 bar) and, therefore, the friction losses are limited. The designs based on the theory of power maximization and on the multi-objective optimization, respectively, are depicted in a T-s diagram; see Fig. 11. 


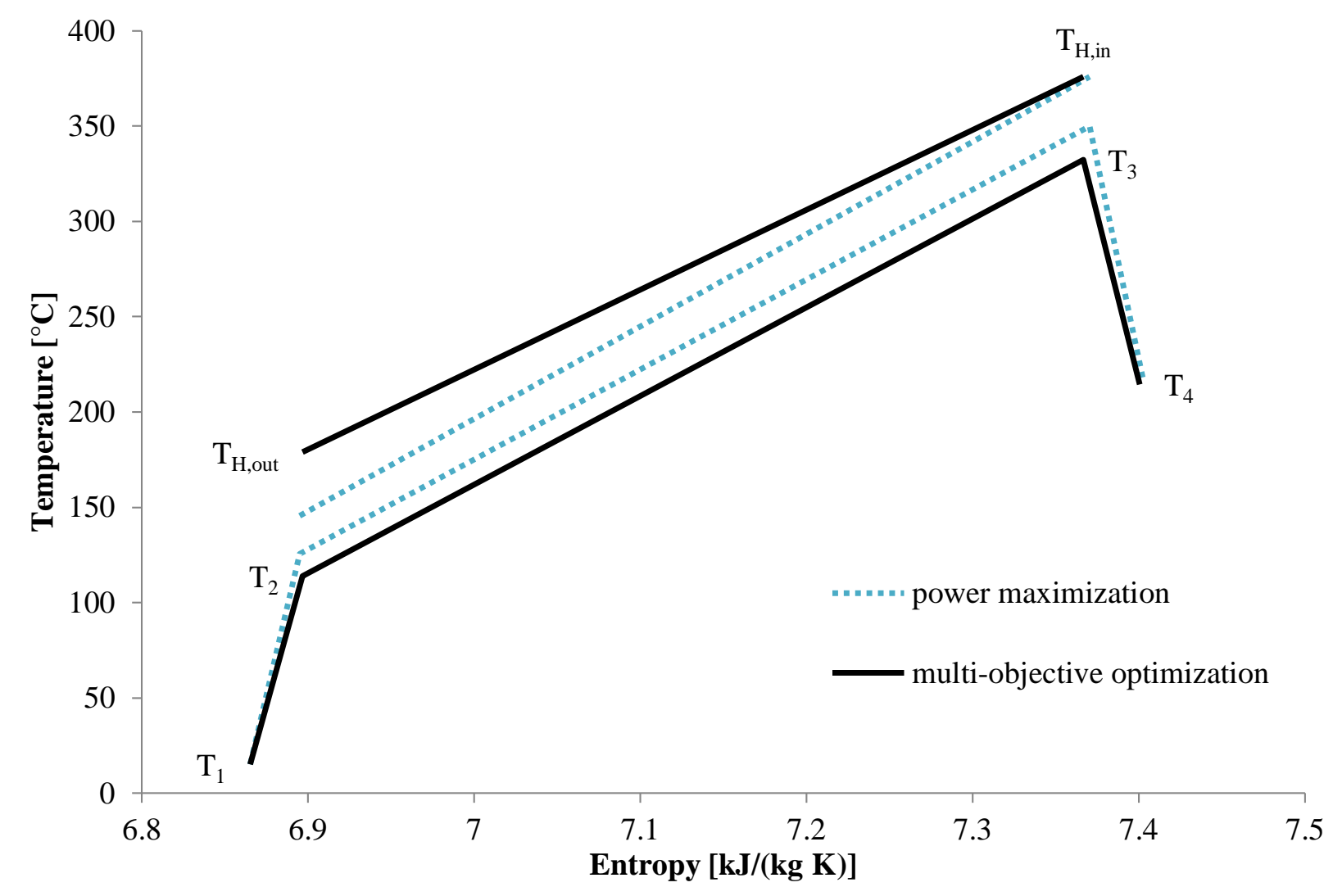

Figure 11. Temperature versus entropy diagram for the designs based on the theory of the power maximization and on the multi-objective optimization approach.

As indicated by the multi-objective optimization the power output and the thermal efficiency of the SGT-500 gas turbine increase from 17014 up to $18997 \mathrm{~kW}$ and from 31.8 up to 35.5\%, respectively. Hence, an increment of 3.7\%-points for the thermal efficiency is obtained. The increment appears to be smaller than the values reported in the open literature. For example, Tveitaskog and Haglind [13] report an increment of around 10.5\%-points for the LM2500 gas turbine, and Poullikkas [11] manages to improve the net power output of the Allison 571-K gas turbine from 5.9 to 7.5 MWe which corresponds to an increment of 27\%. The difference can be caused by two reasons. Firstly, the SGT-500 gas turbine exhibits a lower exhaust gas temperature $\left(376{ }^{\circ} \mathrm{C}\right)$ than the LM2500 and Allison 571-K engines $\left(527^{\circ} \mathrm{C}\right.$ and $582{ }^{\circ} \mathrm{C}$, respectively). Thus, a lower increment in efficiency can be achieved through a bottoming cycle. Furthermore, the cited works focus on maximizing the $\mathrm{ABC}$ performance and do not consider the compactness and the economic 
feasibility. In fact, considering the results of the power maximization listed in section 3.1, a combined net power output of $19807 \mathrm{~kW}$ and a thermal efficiency of $37.0 \%$ are obtained.

The total purchase cost of the $\mathrm{ABC}$ is $2.02 \mathrm{M} \$$ which corresponds to a specific power of $1.02 \mathrm{\$} / \mathrm{W}$. The value matches with the range (0.65-0.9 €/W) reported in Korobitsyn [10]. Figure 12 shows that the purchase cost of an ABC is mainly (56\%) due to the price of the recuperator. Therefore, the focus should be directed on enhancing the heat transfer coefficient of the recuperator in order to decrease the heat transfer area. The second most expensive component is the turbine $(0.57 \mathrm{M} \$)$. The compressor and the electric generator contribute with shares of $12 \%$ and $4 \%$, respectively, to the total price.

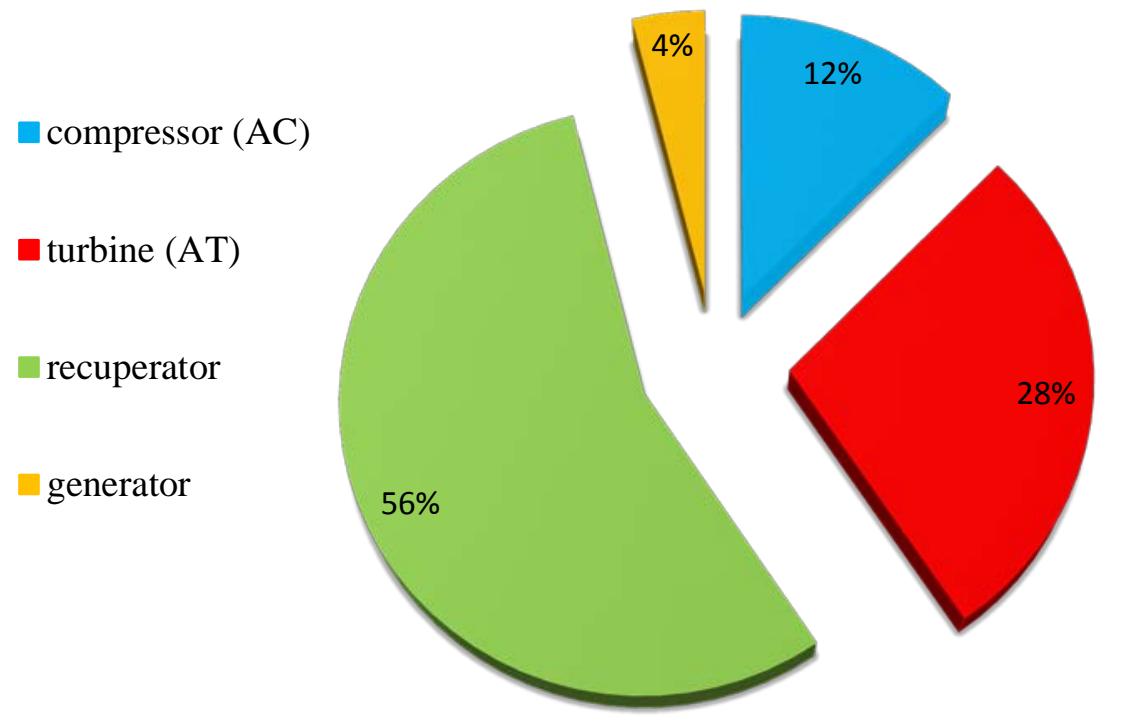

Figure 12. Purchase equipment cost of the compressor, turbine, recuperator and generator in percent of the total purchase cost.

\section{Conclusions}

An air bottoming cycle is design to recover the waste heat from the SGT-500 gas turbine installed on the Draugen platform, Norway, in the North Sea. The theory of power maximization suggests that the optimal 
pressure ratio of the air compressor is 2.80 , leading to an exhaust gas temperature of $145.5^{\circ} \mathrm{C}$. The values can be evaluated using two analytical equations assuming air as an ideal gas and using a constant isentropic exponent. The approach enables boosting the power of the SGT-500 engine by around $16 \%$ in power and 5.2\%-points in thermal efficiency.

Adding the volume of the recuperator and the net present value to the objective functions suggests a different design for the components of the air bottoming cycle. Namely, if the design point that maximizes the net present value is selected, the inlet and outlet temperature differences of the recuperator are increased up to 43.6 ${ }^{\circ} \mathrm{C}$ and $64.7^{\circ} \mathrm{C}$, respectively. In this way, a reasonable volume $\left(127.7 \mathrm{~m}^{3}\right)$ could be calculated by introducing a detailed model of the shell and tube recuperator. For this design, the power output and the thermal efficiency of the bottoming cycle are $800 \mathrm{~kW}$ and 2.0\%-points lower than the values calculated with the theory of power maximization. On the other hand, the suggested design enables obtaining the highest revenue for the investment.

With the present study, the theory of power maximization is extended to consider two crucial aspects (i. e. the compactness and the economic feasibility) in the implementation of an air bottoming cycle as the waste heat recovery unit in off-shore applications.

\section{Acknowledgements}

The funding from the Norwegian Research Council through Petromaks with project number 203404/E30 is acknowledged. We also acknowledge the kind support from Siemens Industrial Turbomachinery AB, Finspång, Sweden for providing necessary technical documentation. 


\section{Nomenclature}

$\begin{array}{ll}\text { Abbreviation } & \\ \text { ABC } & \text { air bottoming cycle } \\ \text { AC } & \text { air bottoming cycle compressor } \\ A T & \text { air bottoming cycle turbine } \\ \text { CC } & \text { combustion chamber } \\ \text { GA } & \text { genetic algorithm } \\ \text { GEN } & \text { generator } \\ \text { HPC } & \text { high-pressure compressor } \\ \text { HPT } & \text { high-pressure turbine } \\ \text { LPC } & \text { low-pressure compressor } \\ \text { LPT } & \text { low-pressure turbine } \\ \text { PT } & \text { power turbine } \\ \text { TIT } & \text { turbine inlet temperature }\end{array}$

Notations

$\Delta T_{1} \quad$ temperature difference at the inlet of the recuperator [K]

$\Delta T_{2} \quad$ temperature difference at the outlet of the recuperator [K]

A $\quad$ area $\left[\mathrm{m}^{2}\right]$

$d \quad$ diameter $[\mathrm{m}]$

$F_{t} \quad$ temperature correction factor

$h \quad$ heat transfer coefficient $\left[\mathrm{kW} /\left(\mathrm{m}^{2} \mathrm{~K}\right)\right]$ or enthalpy $[\mathrm{kJ} / \mathrm{kg}]$

hu utilization factor [hours/year]

I $\quad$ total capital investment [\$]

$i \quad$ year 


\begin{tabular}{|c|c|}
\hline$J$ & array of the objective functions \\
\hline$j_{t h}$ & tube side heat transfer factor \\
\hline$j_{t f}$ & tube side friction factor \\
\hline$j_{s h}$ & shell side heat transfer factor \\
\hline$j_{s f}$ & shell side friction factor \\
\hline$l$ & length $[\mathrm{m}]$ \\
\hline$M$ & operating and maintenance cost factor \\
\hline$m$ & exponent in Eq. (9) \\
\hline$\dot{m}$ & mass flow $[\mathrm{kg} / \mathrm{s}]$ \\
\hline$n$ & number of years \\
\hline$N P V$ & net present value \\
\hline$\dot{P}$ & electric or mechanic power $[\mathrm{kW}]$ \\
\hline$p$ & pressure $[\mathrm{Pa}]$ \\
\hline$p_{t}$ & tube pitch [m] \\
\hline $\operatorname{Pr}=\frac{c_{p} \mu}{\lambda}$ & Prandtl number \\
\hline$q$ & interest factor \\
\hline$\dot{Q}$ & heat rate $[\mathrm{kW}]$ \\
\hline$R$ & yearly income [\$/year] \\
\hline$r_{c}$ & pressure ratio compressor \\
\hline$R e=\frac{\rho u d_{e}}{\mu}$ & Reynolds number \\
\hline$T$ & temperature $[\mathrm{K}]$ \\
\hline$t w$ & thickness [mm] \\
\hline$U$ & heat transfer coefficient $\left[\mathrm{kW} /\left(\mathrm{m}^{2}{ }^{\circ} \mathrm{C}\right)\right]$ \\
\hline$u$ & velocity [m/s] \\
\hline$V$ & volume $\left[\mathrm{m}^{3}\right]$ \\
\hline
\end{tabular}


Greek symbols

$\begin{array}{ll}\Delta & \text { difference } \\ \rho & \text { density }\left[\mathrm{kg} / \mathrm{m}^{3}\right] \\ \lambda & \text { thermal conductivity }\left[\mathrm{kW} /\left(\mathrm{m}^{\circ} \mathrm{C}\right)\right] \\ \mu & \text { viscosity }\left[\mathrm{N} / \mathrm{m}^{2}\right] \\ \eta & \text { efficiency }\end{array}$

\section{Subscripts}

$b \quad$ baffle

C

compressor

$e \quad$ equivalent

el electric

H hot

$i \quad$ inside

id inside dirt coefficient

in inlet

is isentropic

lm logarithmic mean

net net

$o \quad$ outside

od outside dirt coefficient

out outlet

rec recuperator

sw shell wall 
$t$

th

tot

$t w$

w tube or turbine

thermal

total

tube wall

wall 


\section{References}

[1] U.S. Energy Information Administration. Annual Energy Review 2011. DOE/EIA-0384(2011), September 2012 http://www.eia.gov/totalenergy/data/annual/pdf/aer.pdf, 08/02/2013.

[2] De Paepe M. Situation of the ORCNext project. International Symposium on Advanced Waste Heat Valorization Technologies, September 13-14, Kortrijk, Belgium, 2012.

[3] Nguyen T V, Elmegaard B, Pierobon L, Haglind F and Breuhaus P. Modelling and analysis of offshore energy systems on North Sea oil and gas platforms. Proceedings of the $53^{\text {rd }}$ Scandinavian Simulation and Modeling Society conference, October 4-6, 2012, Reykjavik, Iceland.

[4] Ministry of the Environment. The Government is following up on the Climate Agreement. Press release, 08.10.2012, Norway. http://www.regjeringen.no/en/dep/md/press-centre/Press-releases/2012/thegovernment-is-following-up-on-the-cl.html?id=704137. 07/02/2013.

[5] Pierobon L, Rambabu K, Haglind F. Waste heat recovery for offshore applications. ASME 2012 International Mechanical Engineering Congress \& Exposition, IMECE2012, November 9-15, 2012, Houston, Texas, USA.

[6] Farrell W M. Air cycle thermodynamic conversion system, United States Patent Number 4751814; June 1988.

[7] Alderson E D. Air bottoming cycle for coal gasification plant, United States Patent Number 4785621; November 1988. 
[8] Najjar Y S H, Zaamout M S. Performance analysis of gas turbine air-bottoming combined system. Energy Conversion and Management 1996; 37(4): 399-403.

[9] Bolland O, Førde M, Hande B. Air Bottoming Cycle: Use of Gas Turbine Waste Heat for Power Generation. Journal of Engineering for Gas Turbines and Power 1996; 118(2): 359-368.

[10] Korobitsyn M A. Industrial applications of the air bottoming cycle. Energy Conversion and Management 2002; 43:1311-1322.

[11] Poullikkas A. An overview of current and future sustainable gas turbine technologies. Renewable and Sustainable Energy Reviews 2005; 9:409-443.

[12] Ghazikhani M, Passandideh-Fard M, Mousavi M. Two new high-performance cycles for gas turbine with air bottoming. Energy 2011; 36:294-304.

[13] Tveitaskog A K, Haglind F. Optimization of advanced liquid natural gas-fuelled machinery systems for a high-speed ferry. Proceedings of ASME Turbo Expo 2012, GT2012, June 11-15, 2012, Copenhagen, Denmark.

[14] Chmielniak T, Czaja D, Lepszy S. Technical and economic analysis of the gas turbine bottoming cycle. Proceedings of ASME Turbo Expo 2012, GT2012, June 11-15, 2012, Copenhagen, Denmark.

[15] Bejan A. Advanced engineering thermodynamics $3^{\text {rd }}$ Edition. ISBN-13: 978-0-471-67763-5, Wiley, 2006.

[16] The MathWorks, Inc. 2012, General Release Notes for R2012a. 
[17] Lemmon W E, Huber L M, McLinden O M. NIST Reference Fluid Thermodynamic and Transport Properties-REFPROP, Version 9.0, User’s guide. Thermophysical Properties Division, National Institute of Standards and Technology, Boulder, Colorado (USA), 2010.

[18] Valero A, Lozano M A, Serra L, Tsatsaronis G, Pisa J, Frangopoulos C, Von Spakovsky M R. CGAM problem: definition and conventional solution. Energy 1994; 19 (3):279-286.

[19] Lian Z T, Chua K J, Chou S K. A thermoeconomic analysis of biomass energy for trigeneration. Applied Energy 2010; 87:84-95.

[20] Douglas K L. Handbook of Sulfuric Acid Manufacturing. ISBN 0-9738992-0-4, DKL Engineering, 1961.

[21] Richardson J F, Peacock D G. Coulson and Richardson's Chemical Engineering Volume 3 - Chemical and Biochemical Reactors and Process Control (3rd Edition). ISBN 0-7506-4950-X, Elsevier, 2001.

[22] Fakheri A. A General Expression for the Determination of the Log Mean Temperature Correction Factor for Shell and Tube Heat Exchangers. Journal of Heat Transfer 2033; 125(3):527-530.

[23] Kern D Q. Process Heat Transfer. ISBN 0-07-Y85353-3, McGraw-Hill, 1950.

[24] Frank, O. Simplified design procedure for tubular exchangers. Practical aspects of heat transfer, Chem. Eng. Prog. Tech. Manual; Am. Inst. Chem. Eng: 1978.

[25] Pierobon L, Nguyen T V, Larsen U, Haglind F, Elmegaard B. Multi-objective optimization of organic Rankine cycles for waste heat recovery in offshore applications. Energy 2013; 58: 538-549. 
[26] Hall S G. Capital cost targets for heat exchanger networks comprising mixed materials of construction, pressure ratings and exchanger types. Chemical Engineering 1990; 14 (3):319-335.

[27] Leff H S. Thermal efficiency at maximum work output: new results for old engines. American Journal of Physics 1987; 55(7): 602-610.

[28] Mordecai A. Nonlinear Programming: Analysis and Methods. ISBN 0-486-43227-0, Dover Publishing, 2003.

[29] Falkenauer E. Genetic Algorithms and Grouping Problems. ISBN 978-0-471-97150-4, Wiley, 1997.

[30] Kocer F Y. Arora J S. Standardization of steel pole design using discrete optimization. Journal of Structural Engineering 1997; 123(3): 345-349.

[31] Bejan A, Tsatsaronis G, Moran M. Thermal Design and Optimization. Canada, John Wiley \& Sons, Inc.; 1995. ISBN 0-471-58467-3.

[32] Rypdal K. Anthropogenic emissions of the greenhouse gases CO2, CH4 and N2O in Norway. Report 93/24, Central Bureau of Statistics of Norway, Oslo 1993, ISBN 82-537-3917-6. 